\section{Author, text and cultural meaning: Vijay Mishra's Salman Rushdie and the genesis of secrecy}

Media International Australia

$1-5$ (c) The Author(s) 2021 (c) (i)

Article reuse guidelines: sagepub.com/journals-permissions DOI: $10.1177 / 1329878 \times 211046987$

journals.sagepub.com/home/mia

@SAGE

\title{
Karina Aveyard
}

University of East Anglia, UK

Mishra V (2019) Salman Rushdie and the Genesis of Secrecy. London and New York: Bloomsbury. ISBN 978-I3502-II44-5 (paperback), xiv+247pp., A\$I7I.00.

\begin{abstract}
Vijay Mishra's meticulous analysis of the Rushdie Emory Archive - Salman Rushdie and the Genesis of Secrecy - is one of the most significant paperbacks to have been released in humanities publishing in 2021 (originally published in hardback in 2019). In one sense this book might be understood as a literary project, one that enriches understanding of the Rushdie's published works through the perspectives gained from close reading and detailed cross-referencing of Emory's extensive collection of the author's personal papers, unpublished manuscripts, digital materials and ephemera. However, to categorise The Genesis of Secrecy simply in terms of its literary credentials would be to overlook its conceptual and methodological value to wider areas of culture and media research. With this broader frame in mind, this review essay considers the book from an interdisciplinary perspective.
\end{abstract}

\section{Keywords}

Salman Rushdie, the Author, cultural texts, Vijay Mishra, cultural studies

\section{Introduction}

Vijay Mishra's meticulous analysis of the Rushdie Emory Archive - Salman Rushdie and the Genesis of Secrecy - is one of the most significant paperbacks to have been released in humanities publishing in 2021 (originally published in hardback in 2019). In one sense this book might be understood as a literary project, one that enriches understanding of Rushdie's published works through the perspectives gained from close reading and detailed cross-referencing of Emory's extensive collection of the author's personal papers, unpublished manuscripts, digital materials and ephemera. As other reviewers have already noted (for example Ramone, 2020; Stadtler, 2021) Mishra's study illuminates the genesis and development of Rushdie's writing from 
experimentation and innovation with form and style, through to the ideological, literary and theological influences that both frame and give rise to contestation and negotiation in his work.

However, to categorise The Genesis of Secrecy simply in terms of its literary credentials would be to overlook its conceptual and methodological value to wider areas of culture and media research. With this broader frame in mind, this review essay considers the book from an interdisciplinary perspective.

Before proceeding it is important to declare my limitations. I have researched and written on various aspects of film, media consumption and culture, but I am not a literary scholar. I have read far more literature than literary criticism and analysis during my life, although I did once hold ambitions in the latter direction. Entering a Bachelor of Arts degree at the Australian National University in the late 1980s I intended to complete a major in English Literature, a direction I had abandoned in favour of History and Politics by the half-way point of my second year. I no longer recall with any clarity the reasons for this. My enduring memory of English is simply that it seemed dull and required reading far too many books about marriage and the associated social protocols of upper class English life. By contrast History and Politics was where I encountered Marxism, Foucault and learnt about revolutions, and where I joyously discovered there was an intellectual framework that could give form and articulation to my nascent leftist political outlook. If I had realised literary studies could encompass the kind of dynamic and compelling cultural theorisations contained in The Genesis of Secrecy I may well have made different decisions.

\section{Authorship and cultural meaning in The genesis of secrecy}

Reading and analysing the thought and creative work connected with the production of Salman Rushdie's varied oeuvre of publications is an ambitious undertaking - one that has involved Mishra in many hours of careful research in what he identifies as two Archives (the Emory collection and the body of Rushdie's published texts) in order to produce an impressively detailed and insightful study. Rich in literary critique, the book also brings new perspectives and nuance to long standing theoretical debates in this field (and creative cultures more broadly) about how to position the author within critical readings of their texts.

The Genesis of Secrecy invites the reader to consider a series of foundational questions about authors and the acquisition and interpretation of cultural meaning. Two are of particular interest to me. The first has to do with the substance and materiality of cultural texts and the processes through which they come into existence and attain meaning. The second relates to the critical methods used to understand and represent creative production in sociological and technical terms, not so much as acts of industrial labour but in relation to the cultural objects to which these endeavours give rise.

The process of 'knowing' (Dewey and Bentley, 1949) cultural texts through critical investigation necessitates engagement with their endlessly multi-dimensional and multi-faceted formations. It follows that different approaches will produce different accounts of meaning depending on the ontological and epistemological positions that underpin them. Put more simply, as cultural researchers we do not uncover essentialisms but instead discern and construct meaning (at least in part) according to where and how we look.

One of the core propositions of this book is that critical understanding of cultural texts can be enriched by 'looking' at the circumstances in which these objects come into existence, not just what happens after the fact as text/object and audience/reception. As contemplated in The Genesis of Secrecy, this comprises much more than an examination of the efforts and life circumstances of the author as a feted or talented individual. Rather Mishra positions the figure of the 
author as a socially and culturally located self, one that is enmeshed in and directed by a myriad of historically determined material and perceptive subjectivities, not merely contextualised by them. In Rushdie's case this highlights the influences of colonialism and its legacies, and the cultural practices and theologies of Islam. It also follows the development of Rushdie's writing craft, honed through the inspiration and example of other literary figures, and processes of personal experimentation, adaptation and innovation with form and style.

While Roland Barthes blunt provocation regarding the 'death of the author' in literary criticism (1977) is clearly not one that is taken up seriously in The Genesis of Secrecy, Mishra's analysis prompts a return to some of the more nuanced parts of Barthes essay. In particular, how the relationship between the individual writer and their socio-cultural situation might be appropriately conceptualised. As Barthes wrote:

The Author, when believed in, is always conceived of as the past of his own book: book and author stand automatically on a single line divided into a before and an after .... In complete contrast, the modern scriptor is born simultaneously with the text, is in no way equipped with a being either preceding or exceeding the writing, is not the subject with the book as a predictate (1977: 145)

Foucault subsequently suggested the subverted temporalities and material absences of individual production and positionality identified here by Barthes might find some resolution by instead regarding the author as an embodiment of systems and discourses (Foucault, 1998: 217-222). Collectively these ideas have been highly influential and the status of the writer/originator continues to be regarded as conceptually complex and a difficult topic to engage. As Jakob Stougaard-Nielsen's survey of this field observes, the author has tended to 'haunt' the limits of twentieth and twenty-first century literary criticism, rather than occupy a central position in analysis (2019: 270).

Mishra is of course well aware of such arguments and brings his command of literary and cultural theory to the pragmatics of dealing with the Rushdie material. As if directly addressing the kind of concerns outlined by Barthes and Foucault, Mishra unravels deep aspects of Rushdie's creative processes, particularly in the chapters devoted to the novels The Satanic Verses and Midnight's Children. Through these sections the reader gains insight into the complex dualities of the figure of the author, one that cannot be resolved entirely in favour of discourse nor entirely on the side of the self. This is emphasised most clearly in Mishra's analysis of Rushdie's fictional characters, and the ways in which they have developed and evolved with Rushdie over decades, transitioning through multiple guises and reappearing across a number of novels. In The Genesis of Secrecy the reader comes to a sense (metaphysically) of these characters possessing a life force of their own - independent from and often preceding narrative and text, and in moments perhaps even transcending the writer himself. Yet, at the same time, these figures appear paradoxically and simultaneously indivisible from aspects of the Rushdie's individuality.

\section{Voice, intentionality and methodology}

Mishra adds a further dimension to questions of authorship by considering the intentionality (purpose and consciousness) directed towards the production of material textual objects (Bal, 2003: 8) - the complex issue of discerning who or what embodies the intent in Rushdie's work and who/what exactly might be understood as 'speaking' (Barthes, 1977: 142). What is clear from Mishra's careful examination of the Rushdie Emory Archive and in the emphasis of the 
Rushdie passages selected for reproduction in the book is that this is not a straightforward question to answer.

Alongside the activities that might be considered as more directly linked to textual production (such as in the example above), the book suggests the presence of a voice that may be attributed to Rushdie, 'the man' - something more than the cultural and theoretical construct of 'the author', even with all the multiplicitious dimensions the latter implies. This can be discerned particularly in sections interspersed throughout the book that include excerpts from the writer's personal notes about his developing career and popularity, and his writing practice - especially where these passages trace Rushdie's growing sense of his own greatness. These sections humanise Rushdie by demonstrating his susceptibility to ordinary vulnerabilities such as vanity, hubris and love. At the same time, however, in imagining the possibility of this additional dimension to the author, it may be only that I have been tempted into precisely the kind of individual reification Barthes, Foucault and others have theorised against

The concern with intentionality also extends into Mishra's methodological reflections on the Rushdie Emory Archive itself and the materials it holds (accumulated by Rushdie over many years and sold to Emory University for a significant sum). As noted in the book, Rushdie's growing regard for himself encouraged him to collect and preserve documents and other artefacts over several decades, clearly with the belief these would likely be of value in the future, either monetarily or for research purposes, or both. While Rushdie may publicly eschew the behind the scenes of his work - he is quoted as saying " "To me the book at the end' is the important thing, 'the process is not very interesting"" (Mishra 2019: 53) - Mishra points to the inconsistency in this position by the very existence of the Archive and Rushdie's purposeful efforts to create it.

With this in mind Mishra recognises and addresses the Rushdie Emory Archive as a source already partly curated by its subject, constructed and orientated in a direction that accords significance to the individual figure of the author. It is in the perceptiveness of such observations on Mishra's part that the reader might discern a double-meaning in the 'secrecy' title and theme of the book. It is at once a clear reference to the controversy of The Satanic Verses novel, but also evokes the mystery of the Archive itself: operating behind the redacted and embargoed material, but also partly obscured by the opaque processes of how and in what form the Archive came into existence and is rendered discoverable to scholars.

\section{Conclusion}

The Genesis of Secrecy is a compelling and thoroughly progressive book - one that is engaged with and adds new dimensions and perspectives to long standing critical interest in locating and representing meaning at the intersections of the self and the socio-cultural. It is also an exemplar of methodological rigour in its self-aware approach to archival research, and in the processes of conceptually organising its diverse physical materials and digital formats - practices of scholarship that are both explicitly discussed by Mishra and demonstrated in his thoughtful processes of analysis and exposition. This book has relevance and interest for many areas of cultural research and is highly recommended.

\section{Declaration of Conflicting Interests}

The author(s) declared no potential conflicts of interest with respect to the research, authorship, and/or publication of this article. 


\section{Funding}

The author(s) received no financial support for the research, authorship and/or publication of this article.

\section{ORCID iD}

Karina Aveyard (D) https://orcid.org/0000-0002-6543-9271

\section{References}

Bal M (2003) Visual essentialism and the object of visual culture. Journal of Visual Culture 2(1): 5-32.

Barthes R (1977, original essay 1967) The death of the author. In: Barthes R and Heath S (eds) Image-MusicText. London: Fontana Press, pp. 142-148.

Dewey J and Bentley AF (1949) Knowing and the Known. Boston: The Beacon Press.

Foucault M (1998, original essay 1969) What is an author? In: Fabion JD (eds) Aesthetics, Method and Epistemology Essential Works of Foucault 1954-1984 Volume 2. New York: The New Press, 205-222.

Mishra V (2019) Salman Rushdie and the Genesis of Secrecy. London and New York: Bloomsbury.

Ramone J (2020) Salman Rushdie and the Genesis of Secrecy by Vijay Mishra (review). Modern Fiction Studies 66(4): 978-801.

Stadtler F (2021) Book review. The Review of English Studies 72(303): 209-212.

Stougaard-Nielsen J (2019) The author in literary theory and theories of literature. In: I Berensmeyer et al. (eds) The Cambridge Handbook of Literary Authorship. Cambridge: Cambridge University Press. 